\title{
Editorial statement: The first two years of EJGE
}

Diego Varela, University of A Coruña and Alexandru loan Cuza University of lasi

Giacomo Benedetto, Royal Holloway, University of London

Jose Manuel Sanchez-Santos, University of A Coruña

\begin{abstract}
In this editorial statement we explain the developments in the European Journal of Government and Economics in its second year of existence. In this period, the journal has continued its international expansion, entered some new indices and started to experience its impact, as measured by the number of citations in other journals. After two years of publication, we have also learned some lessons that should help us redefine the role of EJGE.
\end{abstract}

\section{JEL classification}

A12; A30; P27

\section{Keywords}

Academic publishing; academic journal; internationalisation; indexing; academic impact 


\section{Introduction}

One year has passed since our last editorial, in which we discussed our efforts to include the journal in some indices in order to improve its visibility and impact. We also discussed the geographical base of the journal, as well as our intention to make it accessible to a broader economic and political science audience by avoiding unnecessary technical oversophistication (Varela et al., 2012a). In the current year, we have continued our work along the lines of expanding the journal base, both geographically and methodologically, and working for inclusion by abstracting and indexing services. We have also harvested our first fruits in terms of academic impact measured by citations received by our papers in other major publications.

In our first editorial we also discussed the shortage of academic journals and the role of EJGE in filling this gap (Varela et al., 2012b). The experience of two years of publication allows us to test this statement and redefine the role of our journal in the current context. The rest of this editorial statement is structured to cover three major issues: the expansion of the journal base, the efforts to improve the journal's indexing and impact, and the contribution of EJGE to the academic world.

\section{Expanding the journal base}

Since the start of this project two years ago, we aimed to be an international journal, as we highlighted in the journal's aims and scope published on our website. In our editorial statement of December 2012 we pointed out that the nine research papers in the first volume featured authors from Germany, Belgium, the US, the UK, France, Spain, Norway, Italy, and Hungary (Varela et al., 2012a). The nine research articles in this volume include authors from four new countries: Finland, Romania, Nigeria and Russia. This means that, not without difficulty in some cases, we are trying to expand the geographical base of the journal.

In our last editorial statement we also aimed to increase the methodological base of the journal in order to make it more accessible to a broader audience. In the first issue of this volume we included a qualitative analysis of the European Commission's role in three pieces of legislation concerning the regulation of financial services (Hartlapp and Rauh, 2013). In the same issue we also included a interesting paper on Ceausescu's population policy based on the historical analysis of archival material, including the minutes of the meetings of the Central Committee of the Romanian Communist Party in 1966 (Soare, 2013). The topic would seem outdated if it were not because only a few days ago the Spanish government approved a legislative proposal to restrict abortion to an extent not since before 1985. Many would like to have access to the minutes of the Spanish Council of Ministers that approved the proposal but, like in the Romanian case, we shall have to wait many years until the secret expires. The current issue of the journal also includes a qualitative analysis of the European Union's Common Agricultural Policy and a historical paper on Russian natalism.

\section{Indexing and impact}

When we started the journal, we set proper indexing as one of our major objectives, in order to assure the visibility of the journal's contents and increase their academic impact (Varela et al., 2012b). In our second editorial statement one year ago we reported the developments in this respect, and mentioned the Directory of Open Access Journals (DOAJ) as our next target (Varela et al., 2012a). Well, after one year we can say that the objective was accomplished, and we are now indexed and abstracted by the DOAJ at a journal and article level. In the meantime, our journal was also indexed by Econis (a German index) and rated by Index Copernicus (a Polish journal index). We also applied for inclusion in 
Latindex (a directory of Latin American, Spanish and Portuguese journals) and are currently waiting for their assessment. Our next major target is Scopus.

Scopus is the second most selective index, after Web of Science, and one of the best ones to increase the visibility of articles and measure their academic impact. One of the general requirements to apply for inclusion in Scopus is to have a publication record of two years, which we meet with the publication of this issue. As in the case of the DOAJ, the assessment procedure will take several months, so in practice it is possible that the two-year requirement will become a three-year one. The other minimum criterion was to have a publication ethics and malpractice statement, which we introduced one year ago.

Scopus selection is carried out by experts using both quantitative and qualitative measures and the selection is partly based on sample documents from the title. The selection criteria are grouped into five categories: journal policy, content, journal standing, regularity, and online availability. The criteria included in each of these broad categories are summarised in Table 1.

Table 1. Scopus journal selection criteria

\begin{tabular}{|c|c|}
\hline Category & Criteria \\
\hline Journal Policy & $\begin{array}{l}\text { Convincing editorial policy } \\
\text { Type of peer review } \\
\text { Diversity in geographical distribution of editors } \\
\text { Diversity in geographical distribution of authors }\end{array}$ \\
\hline Content & $\begin{array}{c}\text { Academic contribution to the field } \\
\text { Clarity of abstracts } \\
\text { Quality and conformity with stated aims and scope } \\
\text { Readability of articles }\end{array}$ \\
\hline Journal Standing & $\begin{array}{c}\text { Citedness of journal articles in Scopus } \\
\text { Editor standing }\end{array}$ \\
\hline Regularity & No delay in the publication schedule \\
\hline Online Availability & $\begin{array}{l}\text { Content available online } \\
\text { English language journal home page available } \\
\text { Quality of journal home page }\end{array}$ \\
\hline
\end{tabular}

Source: Scopus.com.

We agree with the general desirability of the different criteria and we aim to fare well in all of them irrespective of Scopus selection policy. Two of the criteria are clearly quantitative. One of them is the geographical distribution of authors, an area in which we feel we are particularly strong, at least compared to other journals already listed in Scopus. The second quantitative criterion that deserves special attention is the citedness of journal articles in Scopus.

Our journal is still young to assess accurately the number and quality of citations received by its papers. A two year window after the year of publication is generally used as an indicator, but it is clear that in most journals the peak of citations comes later. For instance, in the case of European Union Politics, the peak came in the fourth year (Varela, 2013). In our case, as we are not yet indexed by Scopus or the web of Science, we use Google Scholar to monitor the citations received by our papers, and, at the moment of writing, five of them have received citations. The paper by Fiorino, Galli and Petrarca (2012) on corruption and growth merits special attention. At the time of writing, it already counts five citations, three of which are in journals listed in Scopus (Petrarca and Ricciuti, 2013; Caruso and Baronchelli, 2013; Padovano, 2013). This is a remarkable achievement considering that this paper was published less than a year ago. All in all, the fact that five out of 14 papers have started to receive citations so early is very promising.

\section{Redefining the role of EJGE}

The experience of two years of publication, and the fact that we have had to do everything by ourselves without the help of a professional publisher, has helped us acquaint ourselves with the tasks involved in running an academic journal. It is not 
until one has to do everything by oneself that one realises how much work is involved, and one starts to understand the reasons why it is so expensive for authors (sometimes in terms of money and often in terms of revisions and waiting) to get their work published. It has been hard, but it would be impossible to get the same experience otherwise.

One of the lessons we learned in this process is that reputation building is a slow process, and the quality of the work originally submitted by authors and their willingness to work on the revisions is directly related to this reputation. This is one of the reasons why the journal has depended on the good will of editorial board members who have submitted papers or encouraged others to submit in order to maintain the quality of the first issues of the journal (special thanks to them). And it is also one of the reasons why we have had to work so hard in the constructive review of other papers (special thanks to our reviewers too). For people outside this inner group, the journal is not more than a set of indicators. That is why every little step counts (a new issue published, a new index joined, a new citation received...). We hope that this new issue will also be a small step in this direction.

But irrespective of the initial push from our contacts and the progressive reputation increase of the journal, it is clear that we shall have to be ready to fish in less travelled waters. The need to expand our journal base beyond its current limits should come at no surprise to colleagues familiar with the current geographical distribution of journals, and the current (and projected) demographics of potential authors and readers around the world. There are countries and entire regions (some of them in continental Europe) that are currently undersupplied of quality academic journals. Getting out of the confort zone may be disturbing at first, but research has always benefited from such endeavours.

\section{References}

Caruso, Raul and Adelaide Baronchelli (2013) 'Economic aspects of the complementarity between corruption and crime: evidence from Italy in the period 1996-2005', International Journal of Monetary Economics and Finance 6(2): 24460.

Fiorino, Nadia, Emma Galli and Ilaria Petrarca (2012) 'Corruption and Growth: Evidence from the Italian regions', European Journal of Government and Economics 1(2): 126-44.

Hartlapp, Miriam and Christian Rauh (2013) 'The Commission's internal conditions for social re-regulation: Market efficiency and wider social goals in setting the rules for financial services in Europe', European Journal of Government and Economics 2(1): 25-40.

Padovano, Fabio (2013) 'Distribution of transfers and soft budget spending behaviors: evidence from Italian regions', Public Choice: 1-19.

Petrarca, Ilaria and Roberto Ricciuti (2013) 'The historical economics of corruption and development within Italy', International Journal of Monetary Economics and Finance 6(2): 186-202.

Soare, Florin S. (2013) 'Ceausescu's population policy: a moral or an economic choice between compulsory and voluntary incentivised motherhood?', European Journal of Government and Economics 2(1): 59-78.

Varela, Diego, Giacomo Benedetto and Jose M. Sanchez-Santos (2012a) 'Editorial statement: The first year of the European Journal of Government and Economics', European Journal of Government and Economics 1(2): 103-5.

Varela, Diego, Giacomo Benedetto and Jose M. Sanchez-Santos (2012b) 'Editorial statement: Why do we need a European Journal of Government and Economics?', European Journal of Government and Economics 1(1): 5-8. 
Varela, Diego (2013) 'The contribution of ISI indexing to a paper's citations: Results of a natural experiment', European Political Science 12(2): 245-53. 